\title{
ANÁLISE DO DISCURSO PEDAGÓGICO LITERÁRIO: A MANIPULAÇÃO DOS MANUAIS DIDÁTICOS E IDEOLOGIAS
}

Filipe Moreira ${ }^{1}$

\begin{abstract}
Resumo: $O$ objetivo desta análise não é criticar os livros didáticos demasiadamente já criticados, mas refletir sobre o caráter discursivo ideológico presente nos manuais para 0 ensino de literatura, cuja apreciação deve se constituir, segundo nossa defesa, como arte que proporciona primeiramente prazer a quem a desfruta. Assim, portanto, sugerir, caso sejam necessárias, mudanças na abordagem do ensino, a fim de que o próprio manual possua um discurso sedutor, que agregue, e não doutrinário, que afasta nossos alunos da leitura literária. Para isso tomamos como objeto de análise para este artigo o catálogo do PNLEM/2005 - o texto que norteia os autores de livros didáticos para suas composições de reescritura dos conceitos literários. Analisaremos, brevemente, a apresentação e a resenha do manual Novas Palavras.
\end{abstract}

Palavras-chaves: Discurso. Ideologia. Literatura. Reescritura.

Abstract: The objective of this analysis is not to criticize the didactic books which has already been quite criticized, but to think about the ideological discursive character present in the handbooks for the teaching of the literature, whose appreciation must be constructed, according to our defense, with art that provides at first pleasure to the one who enjoy it. So, therefore, it can suggest, if it's necessary, changes in teaching understandings, so that the guidebook himself has a seductive speech, that adds, not doctrinaire, which moves our students away from the literary reading. Regarding this we take as object of analysis to this article the catalog of the PNLEM/2005 - the text which guides the authors of didactic books to their compositions of rewriting of their literary concepts. We're going to analyze, soon, the presentation and the review of the guidebook "Novas Palavras" (New Words).

Key-words: Speech. Ideology. Literature. Rewriting.

\section{Introdução}

De certo, ainda hoje, o livro didático é instrumento pedagógico muito explorado, sobretudo nas escolas da rede pública, para o ensino dos conteúdos do Ensino Fundamental e Médio regulares. O ensino de literatura só é iniciado efetivamente no Ensino Médio, e é o livro didático intermediário principal da aquisição pelo nosso alunado dos conhecimentos literários. Seria o

\footnotetext{
1 Mestrando em Estudos de Linguagens - Cefet-MG. Bolsista Cefet-MG. E-mail: lipao123@hotmail.com
} 
livro didático, então, um eficiente recurso pedagógico? E para a aquisição dos conhecimentos literários, o livro didático cumpriria sua missão? Nossos alunos tomam a literatura como fonte de prazer, satisfação? O discurso pedagógico literário adotado pelos livros didáticos é um discurso de sedução, que leva nossos alunos a observar a literatura como fonte de prazer? É acerca desse último problema que abalizaremos nossa pesquisa.

Pretendemos analisar o discurso pedagógico literário no que tange à sua constituição ideológica. Queremos caracterizar, a partir das estratégias discursivas no plano do enunciado e da enunciação, as ideias postas e defendidas no discurso e relacioná-las com discursos exteriores; a esta relação dá-se o nome de interdiscurso, àquelas intradiscurso.

O objetivo desta análise não é criticar os livros didáticos demasiadamente já criticados, mas refletir sobre o caráter discursivo ideológico presente nos manuais para o ensino de literatura, cuja apreciação deve se constituir, segundo nossa defesa, como arte que proporciona primeiramente prazer a quem a desfruta. Assim, portanto, sugerir, caso sejam necessárias, mudanças na abordagem do ensino, a fim de que o próprio manual possua um discurso sedutor, que agregue, e não doutrinário, que afasta nossos alunos da leitura literária. Para isso tomamos como objeto de análise para este artigo o catálogo do PNLEM/2005. O texto que norteia os autores de livros didáticos para a composição. Analisaremos, brevemente, a apresentação e a resenha do manual Novas Palavras.

Partimos do suposto de que o discurso adotado nos livros didáticos atende à necessidade de se tratar a leitura literária como a possibilidade de uma dialética prazerosa, na qual o desejo é o fio condutor entre texto e leitor. (cf. Barthes, 1996). Discurso este que supomos também estar presente nos critérios do catálogo do PNLEM/2005. O contrário seria buscar sistematizar os saberes literários - historiografia; versificação; tipos de discurso etc. - antes que haja a fruição na relação texto-leitor. Fator que impede a formação de um leitor ávido de texto literário, assíduo, frequente. 


\section{A Teoria Adotada}

Partimos do conceito de reescritura tal como Lefevere o define - "A tradução é, certamente, uma reescritura do texto original" (Lefevere, 2007, p. 11) - o qual atribuímos ao discurso pedagógico presente nos manuais, que, tratando-se dos conceitos literários, na maioria dos casos, nada mais fazem do que os traduzirem, reescreverem, em um novo suporte retirando-os dos seus textos originais. Neste processo de reescritura configura-se um novo discurso que, como todo discurso, segundo Foucault, revela sua ligação com o desejo e com o poder:

... o discurso - como a psicanálise nos mostrou - não é simplesmente aquilo que manifesta (ou oculta) o desejo; é, também, aquilo que é o objeto do desejo; e visto que - isto a história não cessa de nos ensinar - o discurso não é simplesmente aquilo que traduz as lutas ou os sistemas de dominação, mas aquilo por que, pelo que se luta, o poder do qual nos queremos apoderar. (Foucault, 2001, p. 10)

E o poder a que se faz referência, no que diz respeito ao processo discursivo de reescritura, reflete, indiferente de sua intenção, uma determinada ideologia e poética, as quais se servem para manipulação do discurso para que ele funcione dentro de uma determinada sociedade e de uma forma determinada (Lefevere, 2007).

Reescritura é manipulação, realizada a serviço do poder, e em seu aspecto positivo pode ajudar no desenvolvimento de uma literatura e de uma sociedade. Reescrituras podem introduzir novos conceitos, novos gêneros, novos artifícios... Mas a reescritura pode reprimir a inovação, distorcer e conter... (Lefevere, 2007, p. 11) 
Defendemos que o ensino de literatura deva sempre ser permeado pela fruição do texto literário. Que a atividade literária seja essencialmente prazerosa para que o ensino seja eficaz. Eagleton (1983) afirma que "a razão pela qual a grande maioria das pessoas leem poemas, romances e peças, está no fato de elas encontrarem prazer nesta atividade". Fazemo-nos de acordo com o implícito da asserção, que o prazer encontrado no texto literário é o fator de maior motivação para a leitura do mesmo.

O ensino de literatura, todavia, não se deve fazer simplesmente por leituras e desfrute de textos, não é somente aí que o prazer está. Defendemos que se deve por meio dos textos literários estabelecer uma reflexão acerca dos saberes de nossa sociedade.

Abalizamo-nos, assim, na apreciação de lvete Walti:

A leitura crítica pode ser, então um exercício de libertação e de liberdade. Ler, criticamente, não significa ler sem prazer, antes, o prazer, como já foi dito, advém da luta, do corpo-a-corpo. Mas não é um paradoxo? Penetrar no texto, senti-lo e, ao mesmo tempo, afastar-se dele o suficiente para, às vezes, desmascará-lo? Não é verdade que o amor é cego. $\mathrm{O}$ amor cego é alienante e alienador. Assim também a leitura cega, a leitura dócil. Ler é travar um duelo com o texto ou no texto enquanto campo de batalha, não com o objetivo de destruí-lo nem deixando-se destruir por ele; mas com o objetivo de dialogar, de interagir, de promover trocas. Não seria este 0 processo social ideal - a troca, a interação a relação dinâmica sujeito/objeto? (Walty, 1992, p. 22)

E é essa troca sobre a qual Walti discorre que defendemos nas leituras literárias, que sejam feitas, sobretudo, de modo prazeroso. Pois é pela leitura, por essa batalha travada, que o ser humano moderno entra em contato com as diversas formas de conhecimento e se forma cidadão capacitado para atuar na 
construção de uma sociedade mais igualitária. É por intermédio da literatura, também, que o ser humano alimenta sua sede de ficção e entra no mundo do imaginário, aguçando não somente sua sensibilidade e gosto artístico, mas também sua visão e crítica perante o mundo em que se insere.

A literatura, assim como outras formas de manifestação artística, preenche a re-criação e re-invensão do universo. $O$ "penetrar no mundo das palavras" drummondiano descortina, ao ser humano, o caminho do conhecimento, bem como o gosto e a fruição estética. (Vieira, 1989, p. 13)

Apresenta-se, portanto, o cenário o qual estamos inseridos e investigamos: o discurso pedagógico literário contido nos manuais didáticos, como resultado de um processo de reescritura, e a construção e consolidação desse discurso até que chegue aos docentes, que também fazem parte do processo de construção desse discurso, e, sobretudo, aos discentes. Se esses discursos são para um ensino de literatura cuja obra literária seja apresentada como fonte de prazer. Pensar as manipulações, ideologias e poéticas contidas nesses processos discursivos são objetivos desse artigo. $\mathrm{E}$ fazemos isso a partir dessas teorias.

\section{Cenário de Ideologias que Configuram o Manual - AD Pedagógico do Catálogo do PNLEM}

Para que tenhamos uma leitura mais consistente em torno do que determina a construção de conceitos postos nos livros didáticos e dos fenômenos que acarretam as reescrituras dos conceitos originais recorremos a um dos instrumentos que norteiam a elaboração dos manuais didáticos: Catálogo do Programa Nacional do Livro Didático para o Ensino Médio: PNLEM/2005, construído pelo MEC.

O documento fornecido pelo MEC é direcionado aos profissionais da educação que, na especificidade de sua área de atuação, discerne, a partir das 
análises propostas pelo catálogo, o livro mais adequado a realidade vigente a ser adotado.

Começa-se com uma carta direcionada aos professores, na qual há, em termos gerais, uma apresentação do catálogo. E desde já se explicita o principal critério, para o catálogo do MEC, de avaliação dos manuais: "Para tanto, ele deve [livro didático] ser isento de erros conceituais ou preconceitos, deve incentivar o debate e estimular o trabalho do professor dentro e fora da sala de aula" (Catálogo do PNLEM, 2005, p. 7). Tal afirmação apresenta o livro didático como capaz de estimular do trabalho do professor. Mas e o aluno, pela leitura do livro didático, é capaz de sentir estimulado? Ou melhor, é critério de avaliação o nível de estimulo que o manual provoca nos alunos? Acerca desses e outros questionamentos pauta nossa investigação.

É importante ressaltar que os manuais didáticos que indicados pelo guia, são os manuais que passaram por todos os critérios de avaliação propostos e foram aprovados. Quanto aos critérios são apresentados logo após a carta direcionada aos professores.

Algo chama a atenção nos seguintes parágrafos:

"A avaliação das obras didáticas pelo PNLD teve reflexos importantes na escola e no mercado editorial. A análise dos dados referentes à escolha dos livros pelos professores mostra que a escolha inicialmente recaía sobre os livros menos qualificados e, posteriormente, passou a incidir sobre os mais bem qualificados, apontando o comprometimento dos professores e da escola com a qualidade do material didático oferecido ao aluno.

O mercado editorial também passou por alterações bastante positivas, e a mais significativa delas é a melhoria da qualidade do material enviado para a avaliação. Essa melhoria pôde ser verificada pelo aumento de coleções e de livros recomendados e a redução de obras excluídas. Evidenciou-se, também, uma renovação da produção didática brasileira, isto é, a inclusão de novas 
obras para avaliação. O impacto positivo do PNLD levou o MEC à ampliação das ações de avaliação" ( Catálogo do PNLEM, 2005, p. 8)

As mudanças ocasionadas em virtude da avaliação proposta pelo PNDL, sobretudo as que dizem respeito ao mercado editorial, nos permite atentar para tal fenômeno. $\mathrm{O}$ argumento que se utiliza para justificar tais mudanças é o aumento na qualidade dos manuais, melhoria que, segundo o catálogo, pode ser verificada pelo também aumenta de coleções de livros recomendados e a redução de obras não aceitas. Entretanto nos abalizamos em Lefevere no argumento de que o que determina essas escolhas são antes questões de poder, ideológicas, das instituições e manipulação da fama literária.

Insisto, de minha parte, que o processo que resulta na aceitação ou rejeição, canonização ou não-canonização de trabalhos literários não é dominado pela moda, mas por fatores bastante concretos que são relativamente fáceis de discernir assim que se decide procurar por eles, isto é, assim que se evita a interpretação como o fundamento dos estudos literários e se começa a enfrentar questões como o poder, a ideologia, a instituição e a manipulação. (Lefevere, 1992, p. 14)

Após a carta direcionada aos professores, há uma apresentação daquilo que pretende ser o catálogo. Desde já este expõe um dos critérios centrais de avaliação proposto que gostaríamos de analisar. Dita que os manuais didáticos estejam em consonância com o que determina as Leis de Diretrizes e Bases da Educação.

"A formação dos alunos no ensino médio deve levar em conta fatores diversos, como o respeito ao contexto social, à diversidade e à pluralidade; deve promover o desenvolvimento das capacidades de inferir, argumentar, pesquisar, produzir e deve estar em consonância com as múltiplas finalidades do ensino médio, estabelecidas pela Lei de Diretrizes e Bases da Educação1: 
I - a consolidação e o aprofundamento dos conhecimentos adquiridos no ensino fundamental, possibilitando o prosseguimento dos estudos;

II - a preparação básica para o trabalho e a cidadania do educando, para continuar aprendendo, de modo a ser capaz de se adaptar com flexibilidade às novas condições de ocupação ou aperfeiçoamento posteriores;

III - o aprimoramento do educando como pessoa humana, incluindo a formação ética e o desenvolvimento da autonomia intelectual e do pensamento crítico;

IV - a compreensão dos fundamentos científico-tecnológicos dos processos produtivos, relacionando a teoria e a prática, no ensino de cada disciplina." (Catálogo do PNLEM, 2005, p. 9)

Esse parágrafo em destaque enfoca as quatro principais finalidades apontadas pela LDB para a educação no Ensino Médio. A julgar pela hierarquia em que estão dispostas as finalidades e os possíveis significados acarretados às sentenças, pensemos nas ideologias contidas na lei.

Comecemos, então, por uma leitura no plano da enunciação. A ordem a qual estão dispostos os quatro objetivos centrais, que são balizas para 0 argumento de avaliação do catálogo, supõe uma topicalização das informações.

Ao realizarmos uma leitura no plano do enunciado, veremos que a topicalização lida através do plano da enunciação, surti efeito bastante expressivo no que tange a ideologia vigente para a educação no Ensino Médio.

O primeiro tópico diz respeito ao asseguramento e progresso do estudante diante dos conhecimentos já adquirido. Requisito fundamental em qualquer nível acadêmico. 
O segundo tópico, um pouco mais complexo, vai retratar a formação do aluno para o trabalho. Ou seja, é objetivo no Ensino Médio formar para o mercado de trabalho. Um discurso que vem da necessidade de eficiência e resultado que, a nosso ver, inflexibiliza o que a escola pode proporcionar, que é o saber reflexivo.

Tópico esse que dialoga diretamente com o quarto e último, cuja necessidade de se estimular a realização prática da teoria estudada é recomendada. Talvez seja essa a condição moderna que prenunciava Vilém Flusser.

Aqui surge, porém, um problema conceitual que constitui o núcleo dessas reflexões: segundo as idéias clássicas, a fábrica é o oposto da escola: a "escola" é o lugar da contemplação, do ócio (otium, scholé), e a "fábrica", o lugar da perda da contemplação (negotium, ascholia); a "escola" é nobre, e a "fábrica", desprezível. Mesmo os filhinhos românticos dos fundadores de grandes indústrias compartilhavam dessa opinião clássica. Agora começa a desvelar-se o erro fundamental dos platônicos e dos românticos. Enquanto escola e fábrica estão separadas e se depreciam mutuamente, governa a maluquice industrial. Por outro lado, enquanto os aparelhos eletrônicos continuam expulsando as máquinas, fica evidente que a fábrica não é outra coisa senão escola aplicada, e a escola não é mais que uma fábrica para aquisição de informações. E somente nesse momento o termo homo faber adquire total dignidade.

Isso nos permite formular a pergunta sobre a fábrica do futuro de modo topológico e arquitetônico. A fábrica do futuro deverá ser aquele lugar em que o homem aprenderá, juntamente com os aparelhos eletrônicos, o que, para que e como colocar as coisa em uso. E os futuros arquitetos fabris terão de projetar escolas ou, em termos clássicos, academias, templos de sabedoria. Como deverá ser o aspecto desses templos, se 
estarão materialmente assentados no chão, se flutuarão como objetos semimateriais, se serão quase totalmente imateriais, é uma questão secundária. $\mathrm{O}$ que importa é que a fábrica do futuro deverá ser o lugar em que o Homo faber se converterá em Homo sapiens sapiens, porque reconhecerá que fábrica significa o mesmo que aprender, isto é, adquirir informações, produzi-las e divulgá-las. (Flusser, p.43)

Mas, de acordo com o pensamento de Flusser, se esse é o lugar da fábrica do futuro, então qual será o lugar da escola? Qual tem sido o lugar da escola, de acordo com a necessidade de eficiência que se propõe dela? Seria mesmo escola, ou fábrica? Possivelmente a fábrica do futuro de Flusser.

Sob esses olhares propomos ler as ideologias presentes no discurso que também determina a constituição do livro didático.

Além da apresentação formalizada, no catálogo, na qual alguns itens tomamos por análise, há, a seguir, elencados detalhadamente os critérios de avaliação dos manuais.

Um dos critérios exigidos é que o manual apresente "sintonia com a legislação e os demais instrumentos oficiais que regulamentam e orientam a Educação Nacional" (Lei nº 9. 394/96 Lei de Diretrizes e Bases da Educação, art. 35). Vimos anteriormente a concepção de escola proveniente da LDB e relacionamos com o conceito clássico e moderno de escola, segundo Flusser.

Há também uma consideração no tange à elaboração do livro didático destina ao professor.

Aparentemente não é o que propomos discutir, nosso direcionamento é para o alunado, entretanto, de acordo com as exigências feitas pelo guia, notamos que o professor também é alvo do livro didático que se apresenta como o legítimo detentor do saber. Uma das exigências feitas para o manual destinado ao professor é que ele deve "informar e orientar o professor a respeito de conhecimentos atualizados ou especializados, indispensáveis à 
adequada compreensão de aspectos específicos de uma determinada atividade ou mesmo da proposta pedagógica do livro."

A esta realidade Batista retrata como o lugar subordinado e dependendo do professor no processo de ensino.

[...] os manuais tendem a se organizar como estudos dirigidos, propondo não apenas uma seleção do conteúdo a ser ensinado, mas também o modo de distribuí-lo no tempo escolar - com base numa progressão de unidades -, assim como um conjunto de atividades que introduzem, desenvolvem a matéria e, muitas vezes, avaliam seu domínio pelo aluno. Terminam, por isso, a se dirigir diretamente ao aluno em enunciados e textos ("Faça agora o exercício", "Pergunte a seu professor", "Leia o texto..."), a assumir, sob um ponto de vista discursivo, a voz do professor e, assim, a construir, para o docente, um lugar subordinado e dependente no processo de ensino. (Batista, 1999, p. 552)

E por fim, antes que se apresentem as resenhas do manuais aprovados na seleção, um texto titulado "A escolha do livros".

"Tendo em vista tantas funções, a escolha do livro que irá subsidiar o trabalho dos professores deve ser criteriosa e afinada com as características da escola e dos alunos e com o contexto educacional em que estão inseridos."

Contudo, a escolha a qual o parágrafo acima faz referência, não é livre. Embora o professor e o aluno sejam os leitores a que os manuais didáticos se direcionam, não são os únicos e menos ainda os mais determinantes para a solidificação do produto final. Há neste processo de reescritura da teoria literária para o livro didático uma serie de fatores/leitores determinantes que não essencialmente os alunos e professores. Antes consideremos os editores, coordenadores envolvidos, diretores de escola, avaliadores, etc. E isso se torna determinante na construção de conceitos. 
A reescritura manipula e é eficiente. Mais uma razão, portanto, para estudá-la. De fato, o estudo da reescritura poderá mesmo ser de alguma relevância para além do círculo privilegiado das instituições educacionais, é uma forma de restaurar para o estudo da literatura um pouco da relevância social que os estudos literários como um todo perderam. Os estudantes agora "vivem uma cultura mais manipuladora que os seres humanos jamais experimentaram" (SCHOLES, 1985, p. 15). Estudar os processos relativos à reescritura da literatura não dirá aos estudantes como viver suas vidas (muito mais provável que eles voltarão para o cinema em busca desse tipo de modelo), nem os ensinará a escrever bem, outra justificativa para o ensino tradicional da literatura. Mas poderá servir como uma espécie modelo que lhes possibilitará, até certo ponto, "ver através das manipulações de todos os tipos de textos em todos os tipos de mídia"(SCHOLES, 1985, p.15. O estudo de reescrita não dirá aos estudantes o que fazer, mas poderá mostrar a eles formas de não permitir a outras pessoas que Ihes digam o que fazer. ( Lefevere, 1992, p. 24)

É de acordo com Lefevere que pensamos a análise do Catálogo do Programa Nacional do Livro Didático para o Ensino Médio.

\section{AD Pedagógico da Resenha do Manual Novas Palavras}

No que tange à resenha destinada à análise do manual didático Novas palavras o catálogo começa por tecer comentários ao ensino de literatura oferecido pelo livro.

"Organizado na forma de um compêndio1 de molde tradicional, o livro apresenta, entre suas qualidades, o tratamento dado ao ensino da literatura. Embora pouco inovador, este é assumido com solidez e coesão. Também oferece textos menos conhecidos, evitando a repetição que tem caracterizado muitos manuais de literatura. Trata-se, na grande maioria, de materiais textuais relevantes para a formação do aluno como leitor do texto literário." 
A começar pela por adotar o conceito compêndio ao invés de manual, este, segundo o catálogo, delimitaria por série os conhecimentos a serem apreendidos pelo aluno, já aquele deixaria a cargo do professor a escolha dos conteúdos a serem estudados pelos anos. Ressaltamos que em nossa pesquisa não há esta distinção.

O tratamento dado à literatura é elogiado e caracterizado como sólido e coeso. E, em relação aos textos selecionados, são relevantes, segundo os avaliadores, para a formação do leitor literário.

Embora os avaliadores apontem deficiências na abordagem do ensino de Literatura pelo manual, como, por exemplo, não mencionar outras literaturas em língua portuguesa ou não abordar tendências contemporâneas da literatura de Portugal, de modo geral, a parte do compêndio, como é conceituado pelo manual, destinada a literatura, precisamente metade do volume, é bem conceituada.

"Diante das expectativas atuais para o ensino de literatura, o livro apresenta uma proposta bem convencional: dá grande peso a uma visão panorâmica dos estilos de época, estudados em sua sequência cronológica, do Trovadorismo às "Tendências contemporâneas". Não se limita, porém, à exposição e à exemplificação. Há, na maioria dos capítulos, boa exploração dos textos, o que permite, ao aluno, compreendê-los, apreender sua singularidade e seus sentidos estéticos e culturais.

Nota-se que os avaliadores partem do suposto que alunos, pela "boa exploração de textos" que o manual trás, compreendem, apreendem as singularidades dos textos, seus sentidos estéticos e culturais. Entretanto, tal suposição, não questiona o discurso que apresenta tais textos. Se este levam os alunos a experimentar a fruição estética e não somente a compreensão de conceitos estéticos, que neste caso, não passa de uma suposição, sem nenhum material científico que comprove essa afirmação. 
É garantia para que se forme o leitor de literatura a "compreensão" e "apreensão" isolada da "singularidade e seus sentidos estéticos e culturais"? Ou o leitor literário se formar pelo prazer, gosto em ler, juntamente com o entendimento do material lido e dos conceitos envolvidos?

Teresa Colomer tece comentários sobre a postura adotada muitas vezes pela escola:

Todos estes conteúdos escolares quase sempre são lembrados como áridos, absurdos e desconectados da vida, de modo que cabe refletir sobre a triste impressão que tantas horas de ensino deixaram nessa pobre representação do conhecimento transmitida por uma literatura de séculos. É também impressionante comprovar que são escritores precisamente, ao que tudo indica, aqueles que encontraram em outro lugar o estímulo para dedicar-se posteriormente à literatura, os que nunca mencionam o prazer literário na escola. (Colomer, 2007, p. 7)

Buscamos neste artigo analisar o catálogo em sua constituição ideológica, já que os livros didátios são construídos a partir dessas normas que legalizam a publicação e adoção dos manuais pelas escolas. Portanto, investigar os conceitos e normas postas pelo Catálogo do PNLEM auxilia a compreensão das ideologias postas também nos manuais.

\section{$5 \quad$ Algumas Considerações}

Optamos por analisar o texto que dita às normas de construção dos manuais e, em virtude destas, os avaliam, com o objetivo de configurar um melhor cenário na compreensão dos conceitos reescritos pelo livro didático.

Constatamos que, em sua constituição ideológica, o catálogo reflete um pensamento tecnicista da educação. Retirando da escola o lugar da reflexão e reiterando o caráter prático do ensino, de uma prática eficiente. $O$ discurso que defende que o Ensino Médio, e nele está o livro didático e o ensino de Literatura por estes, deva ser voltado para o mundo do trabalho, retira o caráter 
reflexivo do ensino, muitas vezes o lugar do pensamento. Ora, os estudos literários são de caráter reflexivos cujo direcionamento de ensino se se volta para uma utilização puramente técnica, eficiente, dos conhecimentos, perderá sua essência.

Os pilares da LDB, que consequentemente também são os valores adotados para avaliação dos livros didáticos, analisados por nós já neste artigo apontam essa priorização em fazer da escola lugar para se produzir antes que para se pensar.

Ficou claro na leitura do catálogo que não há uma separação entre ensino de língua e ensino de literatura e, menos ainda, diretrizes especificas para a avaliação ensino de literatura. O problema o qual impulsiona esse artigo - se o ensino de literatura pelos manuais é comunicado por um discurso sedutor, intuído de levar o aluno a sentir prazer na leitura - não é visto ao menos como hipótese nos critérios de avaliação. O que fica claro é a preferência por um ensino que apresente um currículo vasto de conceitos e informações, mas, muitas das vezes, vazio de transformação.

\section{Referências Bibliográficas}

ALVES, Rubem. Conversas com quem gosta de ensinar. 2. ed. São Paulo: Ars Poetica, 1995.

AMARAL, Emília; FERREIRA, Mauro; LEITE, Ricardo; ANTÔNIO, Severino. Novas Palavras, Português - Ensino Médio. 2. ed. São Paulo: FDT, 2003.

BARTHES, Roland. O prazer do texto. Trad. J. Guinsburg. 4. ed. São Paulo: Perspectiva, 1996.

BATISTA, Antônio Augusto G. Um objeto variável e instável: textos, impressos e livros didáticos. Belo Horizonte: UFMG, 1999.

COLOMER, Teresa. Andar entre livros: a leitura literária na escola. Trad.: Laura Sandroni. São Paulo: Global, 2007. 
EAGLETON, J. Teoria da Literatura - Uma Introdução. São Paulo: Martins Fontes, 1983.

FOUCALT, Michel. A ordem do discurso. Trad.: Laura Fraga. 7. ed. São Paulo, Loyola, 2001.

FIORIN, J. L. Linguagem e ideologia. 8. ed. São Paulo: Ática, 2005.

LAJOLO, M. P. Teoria da literatura moderna e ensino de literatura no segundo grau do curso secundário brasileiro. São Paulo: Dissertação de mestrado, Faculdade de Filosofia, Letras e Ciências Humanas - USP, 1975.

LEFEVERE, André. Tradução, Reescrita e Manipulação da Fama Literária. Trad. Claudia Matos Seligmann. Bauru, SP: Edusc, 2007.

FLUSSER, Vilém. O mundo codificado: por uma filosofia do desing e da comunicação. Trad.: Raquel Abi-Sâmara. São Paulo, Cosac Nalfy, 2007.

MARCUSCHI, L.A. Produção textual, análise de gêneros e compreensão. 2. ed. São Paulo: Parábola Editorial, 2008.

MEC, SEMTEC, FNDE. Catálogo do Programa Nacional do Livro Didático para o Ensino Médio: PNLEM/2005 : Língua Portuguesa / [coordenação Egon de Oliveira Rangel]. Brasilia : 2004. Disponível em: unw.fnde.gov.br/...livrodidatico/...guialivrodidaticopnlem2006mg/...

WALTI, Ivete; PAULINO, Graça (org). Teoria da literatura na escola: atualização para professores de $l$ e II graus. Belo Horizonte: UFMG/FALE/Departamento de Semiótica e Teoria da Literatura, 1992.

VIEIRA, Alice. O prazer do texto: perspectivas para o ensino de literatura. São Paulo: EPU, 1989. 